\section{VBR 10}

IN VITRO PROPAGATION OF PRENEOPLASTIC HEPATOCYTES INITIATED IN VIVO BY DIETHYLNITROSAMINE

R. Kerler and H.M. Rabes

Continuous administration of the carcinogen diethylnitrosamine (DEN) to rats in the drinking water $15 \mathrm{mg} / \mathrm{kg} / \mathrm{diel}$ induces hepatowiak, Cancer Res.39:1298-1304,1979). During the preneoplastic latency period enzyme-aberrant foci occur, which develop by clonal growth from a single initiated cell (Rabes et al., Cancer Res.42. nodules and carcinomas. A large variety of alterations has been described for these cells by morphological methods. However, in auring early stages of hepatocarcinogenis it appears necessary to select this cell population fron other normal hepatocytes and to propagate them in vitro to obtain a sufficiently enriched population for specific analysis.

Liver of Wistar AF/Han rats, fed DEN for 60 days, were perfused in situ in the aninal with oxygenized collagenase solution $10.05 \%$ Biol.13:29-83,1976). A cell suspension was obtained which contained about 90 o living cells as determined by trypanblue exclusion. The cells were seeded in palcon plastic lasks in a density of approximately 10 cells/ml in a medium composed of a dem 199 an cre after seeding most adult normal hepatocytes are lost under these conditions, while preneoplastic hepatocytes start growing very slowly in a focal pattern as small epithelial. monolayer plaques. These cells can be harvested and used for biochemical investigations concerning early stages of preneoplasia. In a few of these plaques cells proliferate faster within the first 7 weeks of culture and give rise to transformed foci with a biological behav iour characteristic of tumor cells: they grow with a short cell cycle time; in suspension culture they develop into multicellula spheroics; in soft agar these cells are able to form colonies; after 1.p. injection into thy

作 preneoplastic stages car he delineated between initiation and final tumorigenicity and can be used for the investigation, by means of biochemical and cytogenetic methods, of sequential alterations at different stages of carcinogenesis.

Eathologisches Institut der Universität München,
Thalkirchner Str. 36, D-8000 München 2, F.R.G. cellular carcinomas after about 4 months (H.M. Rabes, W. Szymko$3220-3227,1982$ ) and are regarded as precursor lesions for hepatic in Mg ${ }^{2+}$ free Hanks buffer, $\left.30 \mathrm{~min} ., 37^{\circ} \mathrm{C}\right)(P .0$. Seglen, Methods Cell thus be used

\section{VBR 12}

EFFECT OF HYPERTHERMTA ON THE OXYGENATION OF MULTICELLULAR TUMOR SPHEROIDS

A. Göllner and W. Muiller-Klieser

Changes in tumor oxygenation during hyperthermia are mainly eliciter by temperature-induced variations in both cellular respiration and $\mathrm{O}_{2}$ supply via blood flow. To study heat-dependent changes in tumor oxygenation at constant $\mathrm{O}_{2}$ supply conditions multicellular spheroids were used as in vitro-models of tumor microregions.

Spheroids of EMT6/Ro-cells were cultured in stirred media. Oxygen tension $\left(\mathrm{PO}_{2}\right)$ profiles in these tumor spheroids were recorded with a special microelectrode technique (Mueller-kileser and Sutherland, Cancer Res. $42,237,1982)$. Cellular aggregates with diameters of $400-$ $600 \mathrm{~mm}$ were subjected to heat treatment at 40,42 and 44 ${ }^{\circ} \mathrm{C}$. Before heating and $20,40,60$ and 80 minutes after attainment of the respective temperature $\mathrm{PO}_{2}$ profiles were registered in each individual spheroid investigated. Heating of spheroids for 60 or 80 minutes at $40^{\circ} \mathrm{C}$ resulted in a $30 \%$ decrease of the PO. $i$ the center of the cell aggregates. Warming up to $42^{2}$ or $44^{\circ} \mathrm{C}$ for 20 minutes ied to a pronounced ijlcrease in the central $\mathrm{PO}_{2}$. During maintenance of $42^{\circ} \mathrm{C}$ for up to 80 minutes there was only a gradual decline in central $\mathrm{PO}_{2}$. In contrast, the corresponding values returned to the control level after heating spheroids for 80 minutes at $44^{\circ} \mathrm{C}$. Theoretical analysis of the experimental data revealed that the changes in the central $\mathrm{PO}_{2}$ registered were caused by inverse variations of the $\mathrm{O}_{2}$ consumption rate $Q$ within these spheroids.

The results obtained show that hyperthermia in tumor tissue may be associated with an increase in Q at moderate temperatures which may partly counteract the concommitant enhancement of 0 , delivery through elevated blood flow under these conditions. A transient reduction in $Q$ may occur at higher temperatures partially compensating for a restricted $\mathrm{O}_{2}$ supply via blood flow. Apparently, there is an adaptation of cellular metabolism to heat at $44^{\circ} \mathrm{C}$. The biological mechanism of this adaptation is not known to date and, hence, needs further evaluation.

Supported by the Deutsche Forschungsgemeinschaft (Mu $576 / 2-2)$

\section{VBR 13}

\section{VBR 11}

EFFECT OF N-ETHYL-N-BUTYL-NITROSAMINE ON THE ESOPHAGEAL MUCOSA OF THE RAT - HISTOMETRIC INVESTIGATION OF EARLY TUMOR STAGES.

H.U. Sons, F. Borchard

80 male Wistar rats received an oral application ad libitum of N-ethyl-N-butyl nitrosamine in a concentration of $0.18 \mathrm{~g}$ per litre of drinking water. By a maximum of 112 days after the commencement of exposure to the carcinogen, papillomas of the esophagus appeared. The mucosal changes were compared by microscopy with the results from a control group of 10 male Wistar rats of the same age which had not been exposed to the carcinogen, these examinations being performed at three intervals (up to 48 days, up to 93 days, and up to 112 days after the start of exposure to the carcinogen). The following histomorphometric data were determined with the aid of a Leitz ocular micrometer: the width of the epithelium, the length of the papillary body, the thickness of the horny layer, the number, length and maximum width of the nuclei, and the number of mitoses.

The earliest changes found were an increase in the thickness of the epithelium and the horny layer, and an elongation of the papillary bodies and a broadening of the parabasal cell layer. Later there was a significant thickening of the non-papillomatous epithelium - with a substantial increase in the rates of mitoses in all the epithelial layers -, as well as enlargement of the nucle $i$, especially in the middle and upper layers of the epithelium, and a thickening of the partly parakeratotic horny layer. Some of the papillomatous changes conformed with moderate epithelial dysplasias. Because the exposure duration was too short, no invasive carcinomas were observed, even with the larger tumors.

Dr. Dr. H. U. Sons

Ferdinand-Sauerbruch-Kl in ik Wuppertal Arrenberger Str. 20/56

D-5600 Wuppertal
ANTI TUMOR ACTIVITY OF P-AMINOBENZ OYL-O-PHENYLENEDIAMINE (GOE 1734) ON THE MXT MAMMARY TUMOR

W.J.Zeller, T. Klenner, M.R. Berger

p-aminobenzoyl-o-phenylenediamine (Goe 1734) is a new $N$-phenylbenzamide derivative with unknown mechanism of action. In rapidly proliferating transplanted tumor models Goe 1734 was ineffective, whereas slowly proliferating tumors, especially autochthonous models, showed significant response. We investigated Goe 1734 on the MXT mammary tumor in different stages of tumor development. a: early stage; start of daily treatment one day after s.c. inoculation of $10 \mathrm{mg}$ tumor tissue; dosage: $3 \times 20,2 \times 30$, or $1 \times 60 \mathrm{mg} / \mathrm{kg}$. b: advanced stage; start of daily treatment 12 days after s.c. inoculation of $30 \mathrm{mg}$ tumor tissue. At this time point the mean tumor volume was about $400 \mathrm{~mm}^{3}$; dosage: $1 \times 30$, $2 \times 30$ or $1 \times 60 \mathrm{mg} / \mathrm{kg}$. Treatment was given per os. In early and advanced stages tumor growth inhibition was significant $(>60 \%)$ at optimal dosage compared to untreated controls. For instance: Early: $T / C=0.32$ after $2 \times 30$ $\mathrm{mg} / \mathrm{kg}$ daily $\mathrm{x} 12$ days; advanced: $\mathrm{T} / \mathrm{C}=0.38$ after $60 \mathrm{mg} / \mathrm{kg}$ daily $\times 12$ days. $(\mathrm{T} / \mathrm{C}=$ ratio of mean tumor volume in treated animals to controls). The results are interesting since the significant activity of Goe 1734 in autochthonous mammary tumors can also be observed in the transplanted model (volume doubling time about 4 days), which offers some advantages for further studies, especially with regard to expenditure.

Institut für Toxikologie und Chemotherapie, Deutsches Krebsforschungszentrum, Im Neuenheimer Feld 280, D-6900 Heidelberg 